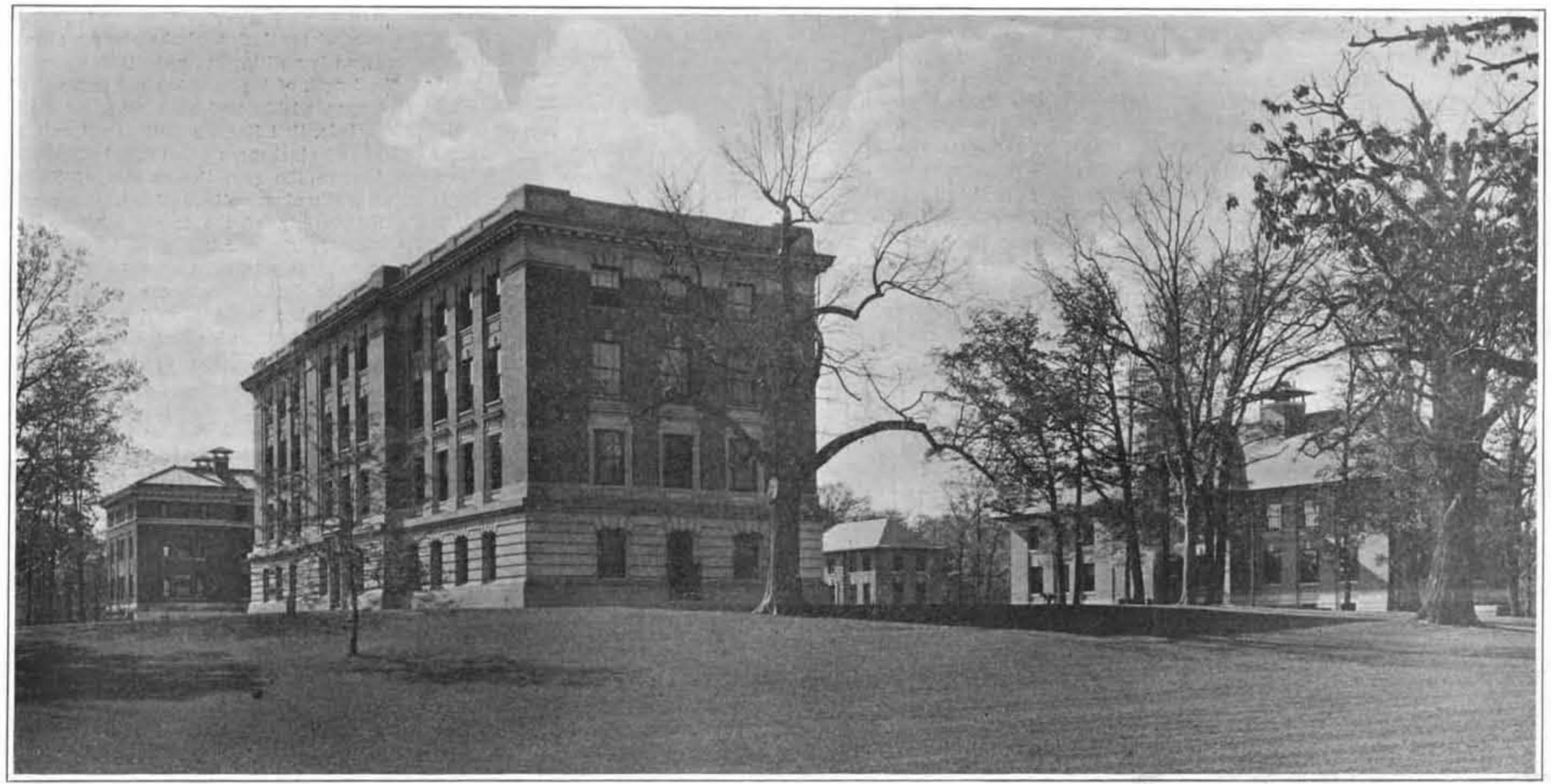

\title{
The National Bureau of Standards and Its Work
}

\section{A Survey of Its Scope and Function}

\section{By S. W. Stratton}

At a meeting of the Ensineers' society of Western, Pa., held a little while ayo, Dr. S. W. Stratten, the Director of the Bureau of Standards in Washington ave a survey of the general scope and function of the work of the Bureau. This was published in the pro ceedings of the society, and in view of its great na tional and scientific interest, is roproduced here in slightly abridged form.

THose who have been engaged to any extent in investigative work in physics, chemistry, or enginesr ing know that one of the first requisites is a sho and power lant, with facilities for designing and constructing apparatus. Hence the first building certed for the National Bureau of Standards was the al building 50 by 150 feet, three stories high, the first floor of which is occupied by the power plant including the nower, electric generators, ums, refrigeration plant and other general facilities of this kind. The corps of mechanicians includes skilled instrument makers, men trained in the construction of precision apparatus and in the working of all kinds of materials. T• begin with, only a portion of one floor was given to the shop the remainder being devoted to various lines of work which in the future would be taken care -f elsewhere.

The second building, built soon after the first one is a substantial hysical and chemical laboratory about 60 by 200 feet and four stories high. The two lower floors are devoted to hysical testing and in vestigations; the third floor is given over to administrative uroses; and the fourth rovides temporarily for the chemical laborateries. Scarcely a roblem is taken up in connection with standards or the proper.
ties of materials that does not involve work of the ties of materials that does not involve work of the work is done in the chemical laboratory. This floo rovides sufficient space for the present, but the chemical staff of the Bureau is rapidly being increased and a new chemical laboratory must soon be pro vided.

The third large laboratery built was completed last year. Its dimensions are practically the same as those of the hysical laboratory. This building pro vides space for investigations and tests of structural enfineering, and miscellaneous materials; the metal lurgical work will be developed in this building.

At the last session of Congress the construction "i fourth laboratory was authorized. It will be a build ing similar in size and style to those already built and will he devoted entirely to electricity but wlll afford additional room for other sections by the vaca tion of space now occupied in the present building.

There is alsø a small, two-story laboratory devoted to the liquefaction of gases, the production of hlgh pressures and low temperatures.
The Bureau has three branch laboratories, the prinipal one being in Pittsburgh.

In standards of length there is first the primary standard, carefully preserved in a fireproof vault and never used except in comparisons with the working - secondary standard which is of the same material and construction as the rimary. If the secondary.

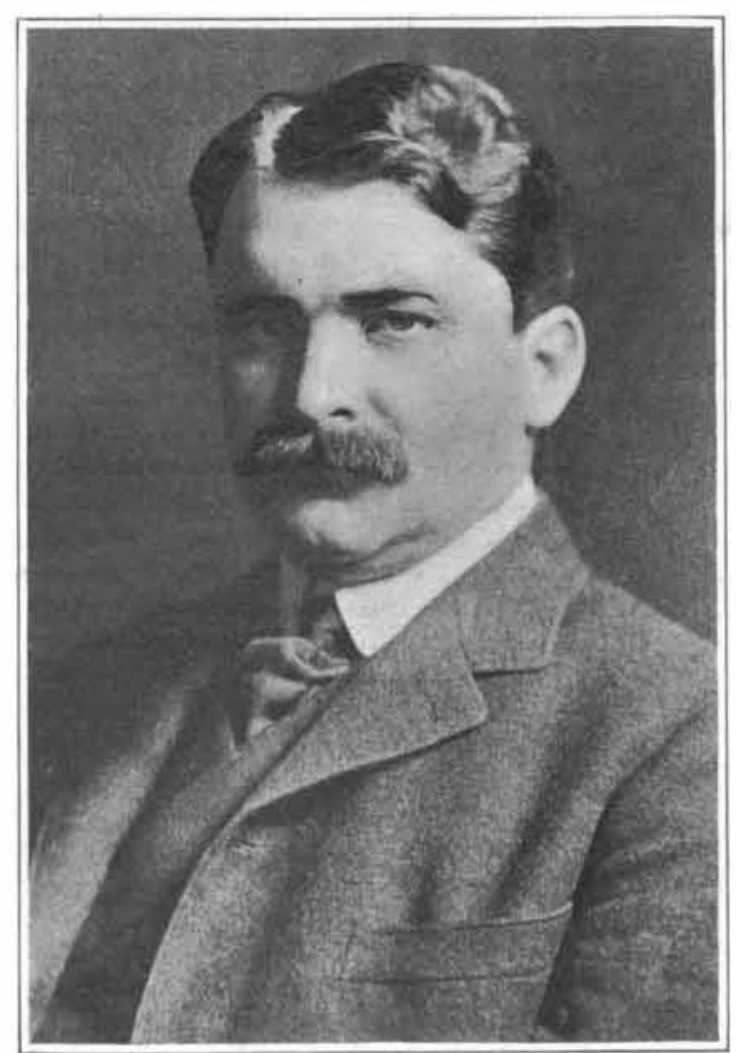

Dr. S. W. Stratton, Director of the Bureau.

-r working, standard should be subjected to any unusual treatment or if its permanence should be suspected in any way it would be compared with the primary standard. Again, there is the secondary standard which is subdivided. This process of subdi. vision is one of the most difficult in the science of metrology. There is alsø a working standard suit. able for comparison with end standards, and, finally, the standards composed of multiples of the unit used in establishing base lines and in the testing of engi. neers' tapes. The problem of building up these mul tiples is as difficult as the production of the subdivisions.

For comparing one standard of length with another a comparator is used In this particular case the two standards are placed in a box, the temperature of
Which is constant within a small fraction of a degres. First one ar and then the other is brought under the two microscopes mounted near the ends of the heavy bar. This support for the microscopes is constructed of the nickel-steel alloy known as "Invar" which has practically a zero temperature coeficient at ordinary temperatures. There is alsø a comparator designed for the purpose of comparing line standards with en standards, a rather difficult roblem, and entirely different from the comparison of line standards with each other and requiring different apparatus.

The same conditions obtain as to standards of mass and their comparisen. There is the primary standard, reserved solely as a check upon the working standards, and the construction of the subdivisions and multiples of the unit, no less tedious and laborious than the same roblems in connection with length For comparisons of mass a wide range of balances is necessary, each with a sensitiveness and capacity suit. able for the work it is to do. The first of the pres-ision series is a small balance carrying a total load of but 10 grammes and sensitive to the thousandth part -f a milligramme; that is to say, it is sensitive to - a mart in ten million of its total load. There are alsø alances having capacities of 100 to 1.000 grammes, and the largest with a capacity of $20 \mathrm{kil}$ grammes and sensitive to one milligranme, or on part in twenty million.

The standard troy pound was brought over from England to this country in 1820 and was prescribed by Congress as the standard to be used by the Mint in coining. It is kept at the Mint in Fhiladelphia and every year the Assay Commission compares the weights of the Mint with it. At the last session of Congress this standard was abolished and the coinage referred to the standards of the Bureau of Standards, in common with all other measurements of mass throughout the country.

As we pass to the different branches of hysical measurements, as, for example, electricity, we find several different uantities to be measured, each re senting the same reblems as to the standards and the means for their comparisens as we find in length and mass. There is the standard cell used in meas. and mass. There is the standard cell used in meas. ure electromotive force; the silver volta neter, the rimeasurements of current; the mercury ohm dards of capacity inductance, and magnetism. Ea. ents exactly the same roblen as to primary and working standards, subdivisions and multiples, and the apparatus and methods for their comparisen, as the standards previously mentioned. The mercury $\bullet \mathrm{hm}$ is a definite standard of resist ance, built u according to exact specifications. It is a laboratory standard and requires for its construction the most precise measurements that it is possible to 


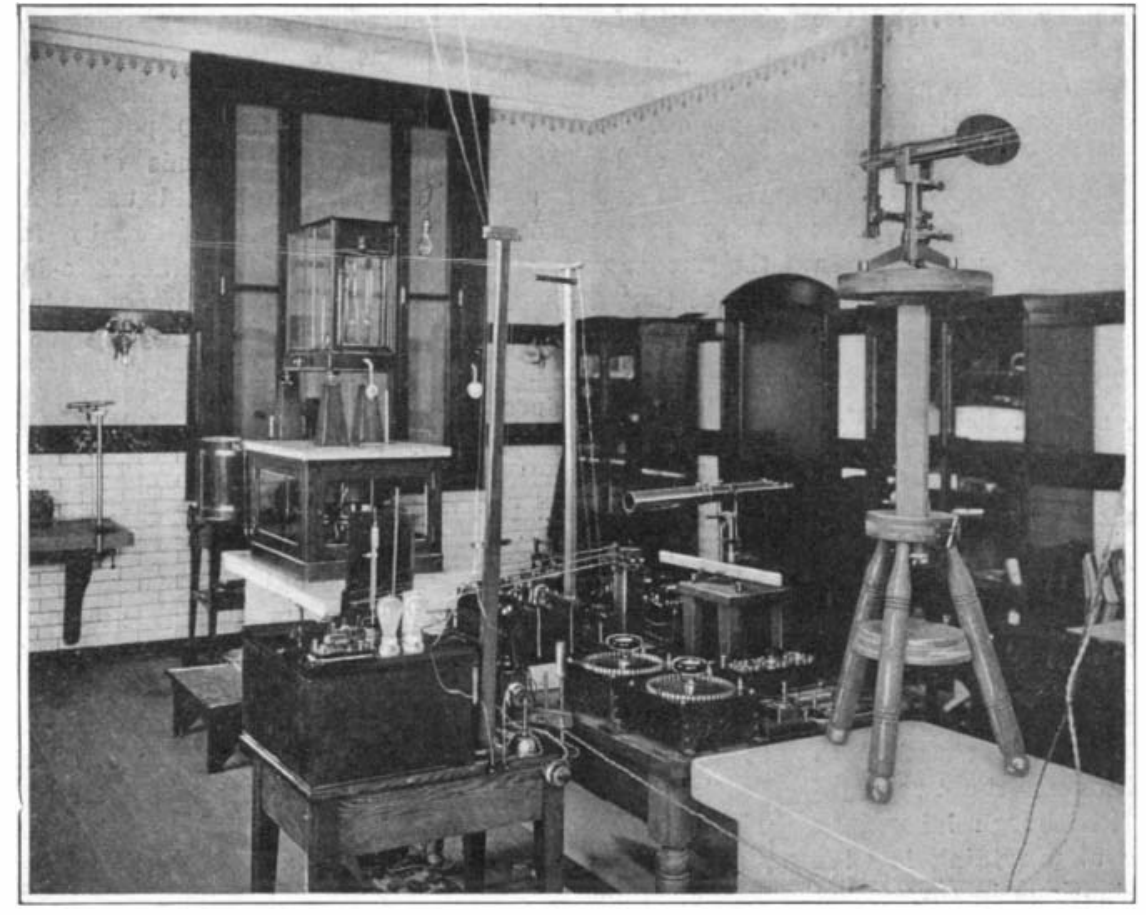

Apparatus for Determining the Unit of Electric Current in Absolute Measure.

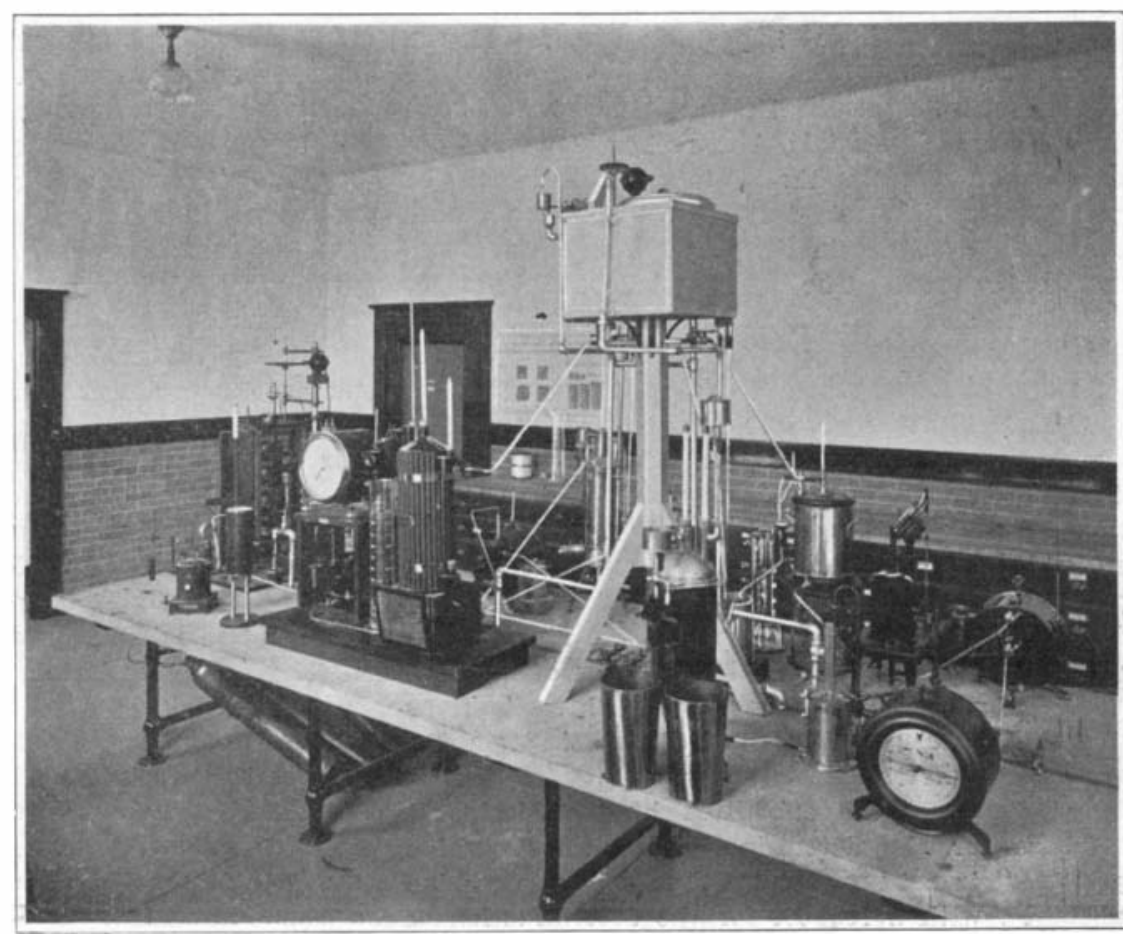

The Gas-Calorimeter Room. make in length and mass. When constructed it is unsuitable as a working standard, hence copies must be made of more convenient material, such as metal wires. The construction of these working standards of resistance is an exceedingly difficult one, involvin the properties of alloys and difficult problems of manipulation. In this, as in the other cases, standards representing the subdivisions and multiples must constructed. constructed. Special apparatus the purpose of comparing these electrical standards with one another, and bears precisely the same relation to such measures as the balance does to the measurements of mass. Formerly it was not possible to obtain as high a degree of accuracy as desired in the construction and intercomparison of electrical standards of the various countries; but great improvement is now being made in this direction. Recently the Bureau constructed three or four standards of rcsistance for international comparison. These were compared with the national standards of England, France, and Germany, and in no case was the differ ence greater than one part in a million, and in most cases it was less. This order of accuracy is nearly equal to that obtained in measurements of length and mass; but to obtain it has necessitated a large amoun of the most difficult work.

The determination of the value of the ampere is one of the most difficult problems in connection with electrical units, requiring for its solution the most delicate instruments and the highest order of manipulative skill. The most minute precautions are taken in this investigation, even to providing a circulation of wate in the coils to remove the heat generated in them while the current is flowing. The values obtained with this instrument are of an extremely high order of accuracy and are taken not only as a basis of all measurements of electric currents but for comparison with the same results of other countries.

The silver voltameter is used as the secondary or working standard in current measurements and it study and development is one of the most importan electrical problems now in progress at the Bureau. Two years ago, at an international conference held at London for the purpose of re-defining the electrical units, a committee composed of members of the staff of the four national laboratories was appointed to of the four national laboratories was appointed to
prepare specifications of the electrical units and to prepare specifications of the electrical units and to
determine their values. This committee met last May determine their values. This committee met last May at the Bureau of Standards to outline and carry on their investigations. The wisdom of this plan was same conditions they were soon able to come to practical agreement; whereas had they worked apart in their various laboratories it is very certain that there would have been a great deal of delay, and the difficulty of securing agreement would have been greatly magnified. During the investigation a great many important questions arose which it would have been very difficult to solve by correspondence, but which were easily settled by the men working together. This case illustrates also the importance of co-opera-

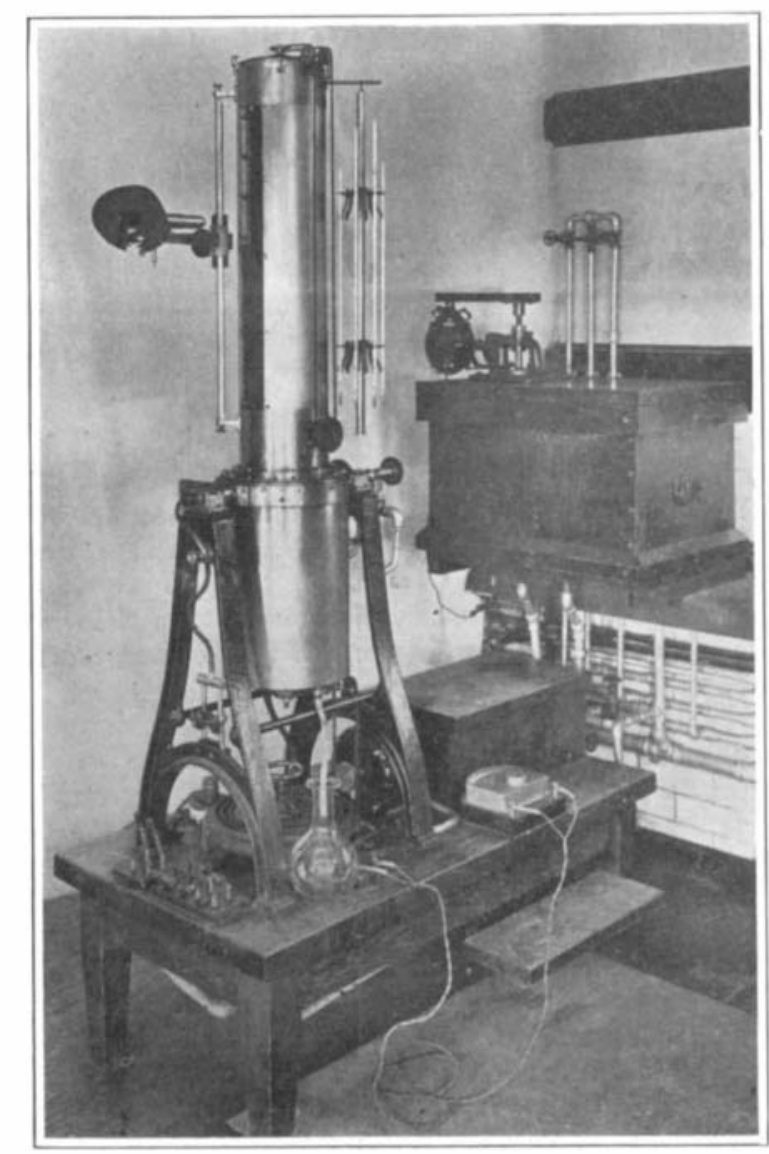

Comparator in Which Mercury Thermometers are Com pared with Standard Instruments.

tion in such investigations in order to establish fundamental units on an international liasis.

Measurements of inductance and capacity, with which we were unfamiliar a few years since, have now become very important in connection with telephony, wireless telegraphy and long distance transmission, and the Bureau has in progress at present a large amount of work in connection with the standard methods of measuring inductance and capacity.

There is perhaps no other standard of measurement on as poor a basis as that of light. The incandescent lamp properly seasoned and used at a certain period of its life is used as a secondary standard, as such it is far superior to our primary standards; but it cannot be used as a primary standard as it is not reproducible.

When the Bureau first took up its work in photometry it found that there was not sufficient agreement between the products of the various lamp companies, caused no doubt by a difference in their standards, and that the gas and electric candle-power differed by three or four per cent. By co-operating with the lamp manufacturers and furnishing them with accurate working standards they have been enabled to remedy this defect. Through the efforts of the Bureau the -power has been adopt land, France, and the United States. The unit of Germany is different, but it bears a definite relation to the international unit. In addition to maintaining the standards the Bureau has developed methods and apparatus for the rapid and accurate measurement of candle-power and tests commercially all of the incandescent lamps purchased by the various departments of the government.

The variety and complexity of apparatus involved in measurements of heat are no less than those in electricity or the other branches of physical science. The degree is necessarily the same, regardless of the method of measurement; but for each range of temperature there is an entirely different method of measurement, involving totally different principles. There is the mercurial thermometer for ordinary temperatures, some reading almost as high as the point ot which the glass softens; temperatures, involving measurements of electromotive force; and optical pyrometers for still higher temperatures, involving optical principles and radiation constants. For low temperatures platinum resistance thermometers are used, depending upon measurement of electrical resistance. Hence, the testing of temperature measuring apparatus includes a wide range of physical principles and methods and they must all be referred to the same standard, the ideal gas thermometer.

The division of heat and thermometry is one of the largest sections of the Bureau's work. Its work also includes the determination of heat constants and the thermal properties of materials, such as specific heats, latent heats, melting points, coefficients of expansion, etc. These data are frequently as important to engi.

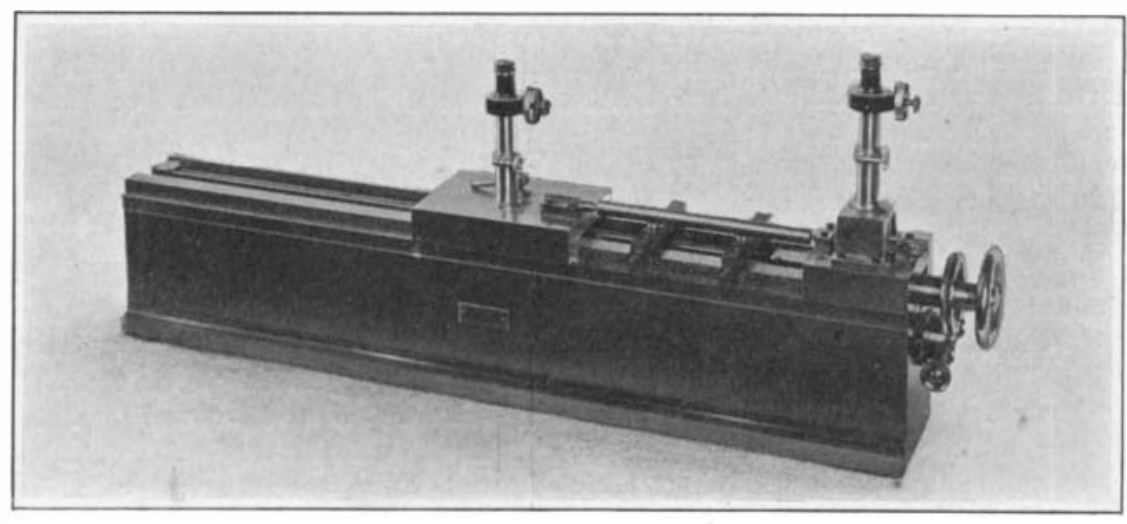

Apparatus for Comparing Line Standards of Length with End-Standards.

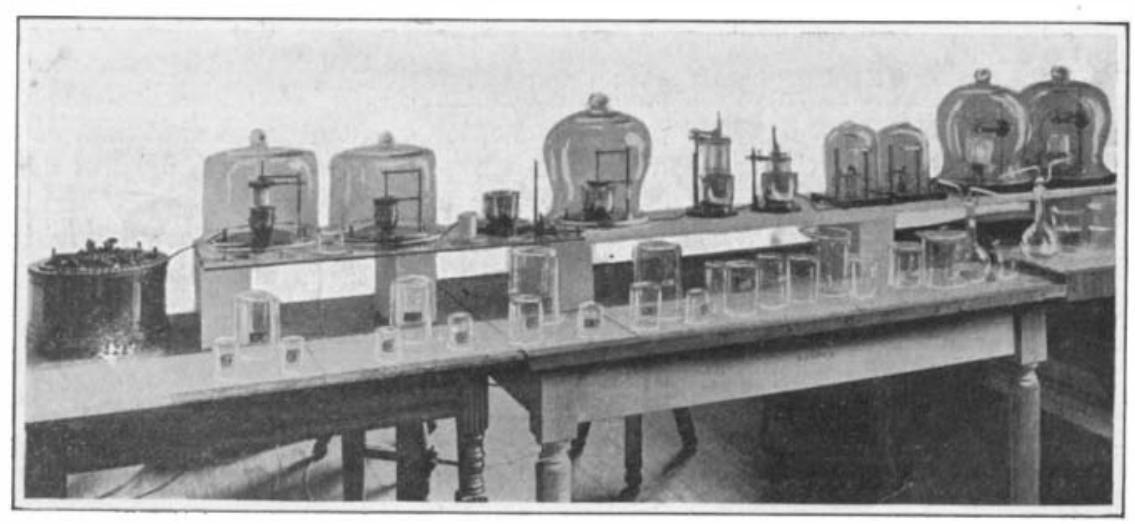

Apparatus Used in the Recent International Determin ation of the Unit of Electric Current. 
neers as standards of measurement, and their determination constitutes an important feature of the Bureau's activities.

The organization of the Bureau is not based upon definite lines of materials, but rather upon definite kinds of measurements; that is to say, a material, th properties of which it is desired to determine, would be assigned to experts in the particular field of measurements required. The designation "Engineer of Tests" does not appear in the Bureau's staff.

The heat and thermometry division is equipped for the testing of thermocouples and pyrometers of all kinds. It is also prepared to furnish pure materials of known melting points, to be used in the verification of instruments. It is carrying on extensive calor metric experiments, in which the different forms of calorimeters are being compared. Investigations are in progress with a view to establishing the heat values of different substances, to be used in the standardization of calorimeters; also the heat values of the constituents of fuel gases. In addition, investigation are carried on for the purpose of securing general values and properties.

Many substances are submitted by manufacturer and others for the determination of their specific properties, it is not unusual for the Bureau to receive a substance, with a request for the determination of one or several of the following properties: tensile strength, hardness, density, heat and electrical conductivities, resistance, specific heat, coefficient of $\mathrm{ex}$ pansion, melting point, and emissivity, etc. In new alloys many or all these properties are needed.

Investigations are in progress with the bolometer of determining more accurately the so-called radiaon constants, transpare

missivity of materials.

Among the various investigations now in progres of interest to engineers may be mentioned the following: A study of the electrolytic effects on water and gas pipes, the reinforcing of concrete, conduits, and other underground metal work; the fire resisting properties of materials; determination of stresses in the members of bridges, buildings, and other structures, by means of accurate strain measurements; methods of waterproofing and damp-proofing cement,
etc. Tables of conductivities have just been prepared etc. Tables of conductivities have just been prepared
for the American Institute of Electrical Engineers from data secured by the examination of a large num ber of samples of commercial copper.

The bureau will continue at its Pittsburgh laboratories (formerly in charge of the Technologic Branch of the Geological Survey) the investigation in connection with the heavier structural materials, including metals, clay products, stone, lime, cement, etc. If is not the purpose of the Bureau to duplicate in Wash ington the work done at Pittsburgh, but rather to establish a close relationship between the two labo ratories. The facilities of the Pittsburgh laboratory are being extended with a view to providing it with a complete equipment for investigations in connection with the above materials. A permanent site and new buildings should be acquired at the earliest opportunity, and the work organized on a scale commen surate with its importance. The ten-million pound testing machine, designed and constructed by $\mathrm{Mr}$ Olsen while the Pittsburgh laboratories were unde the direction of the Geological Survey, is being in stalled at Pittsburgh and will soon be ready for use. This will be properly housed and equipped with the cranes, tools and apparatus for its operation. At Washington two new testing machines of the Emer type are being installed, one of 250,000 pounds ca pacity and the other of $2,300,000$ pounds capacity. While these machines are necessary and useful in many investigations of structural materials, by far the greater part of the data needed by engineers to-day is not that derived by the use of the testing machine, but by means of the most difficult investigations covering the entire field of chemical and physical science.

The Bureau does not plan to enter the field of com mercial testing, especially in localities provided with testing laboratories, excepting in referee work and in the unusual and more difficult tests not provided for in such laboratories.

The Bureau tests a large amount of apparatus and materials purchased by the government, to ascertain whether or not it complies with specifications; this work, in addition to what it saves the government by placing its purchases upon an entirely different basis assists the Bureau greatly in the preparation of specifications, and the development of methods of testing. The benefits of this experience will be given to the public in the form of bulletins, circulars, and other published matter.

It would be out of place at this time to dwell to any great extent upon the plans of the future; but the Bureau earnestly solicits the aid and advice of the engineers at Pittsburgh, and especially the members of the Engineers' Society, in establishing its work along the lines that will be of the greatest assistance to the industries of our country.

\section{The Saw and How to Use It on Wood and Metal*}

\section{Useful Hints for the Workshop By M. Cole}

THE oldest form of saw was a jagged-edged flint, set in a handle of bone or wood. Those of a later date were of bronze, and in use before iron was used for industrial purposes, being too scarce and valuable for other purposes than weapons. In the middle ages, when steel was still very dear, the saws and many other tools were made from iron and case-hardened, a method in practice until a comparatively recent date. Saws of these classes were however, little more than narrow files. They did not make a clean cut, but scraped away the wood, etc., in fragments. The modern saw consists of a number of small knives, each having a properly sharpened cutting
edge (terminating in a point), each of which makes a edge (terminating in a point), each of which makes a
clean cut. One result of the low quality of the old saws was that they had to be used to cut in the pull stroke, instead of in the push stroke as modern ones do. Som of those now in use, cut with both strokes, but these are used only for rough, coarse work. The teeth of these old saws were consequently in the opposite direction to those we use, and this style of saw is still used by many eastern nations. A low quality metal will stand the pul stroke, but would break on attempting to cut by pushing it. Those narrow saws that are strained in a frame, such as fret saws, sweep saws, etc., are used in this way to cut while pulled towards the worker. If - used the other way, they soon break, of ten at the first attempt. Hack saws for cutting metal are among the reversed ones.

Saws in general use are of the following classes: hand saws (so called to distinguish them from the two-handed pit saws, etc.), consisting of a flat blade and pierced handle.

1. Ripping saw or rip saw with coarse teeth, used for cutting soft wood in the direction of the grain. These cut rapidly, and the widely spaced teeth do not clog so soon as those of a finer saw would. They are, however, of little use with hard wood or for cutting across the grain.

2. Cross-cut saw, or more generally called hand saw, and if with fine teeth, panel saw. This is the shape that does most of the cutting in joiners' or cabinet makers' workshops.

Key hole saw, a smaller form of the hand saw, terminating in a point, so as to enter in a hole made with a centerbit. A variety of this is the pad saw, having a round handle with hole through it lengthwise, into which the blade fits when not in use. When used, the blade is held by two screws in the ferrule of the handle. Both of these saws are of very soft steel, so that they bend when one of ordinary temper of the same section would break. It would be an advantage if these saws were made to cut in the pull instead of the push stroke.

Backed Saws. In cutting fine work, in order to get a very narrow saw-cut, a saw with a thin blade must be too weak for the purpose, and also liable to bend in * Reprinted from the "Electrician and Mechanic." using. They are, therefore, strengthened by a rib of brass or iron, having a groove in its length into which one edge of the blade fits. These must be used with care to avoid buckling or bending the blade. They are made in many sizes, from 8 to 24 inches long for various requirements of cabinet makers, picture framers, etc. others much smaller, 3 to 6 inches long, with blades little thicker than note paper. Those most used are: 1. Tenon or dove-tail saw, 8 to 16 inches long, having from 8 to 16 tooth points to the inch, and backed with brass or iron. The smaller sizes have open handles, the larger ones closed.

2. Straight-handled back saws, a smaller form of dovetail saw, with round handle, very thin blade and small teeth, suitable for delicate work.

3. Metal cutting backed saw or ward saw, much used by locksmiths, etc., in preference to the hack saws in dearer than the thin saw.

Tension saws, consisting of a narrow blade strained in a frame by a spring, screw, or twisted cord.

1. Sweep or bow saws. The blade, sometimes less than one-quarter of an inch in width, is strained in a wooden frame. Its narrowness enables it to cut in a curve. It is much used with broader blades on the Continentinstead of the hand saw; also for rough work, such as cutting up logs of firewood, for which purpose it has large teeth far apart, so as not to clog. Some are so arranged that the blade

cut sideways to the frame. 2 . Fret saws for cutting very thin
by the spring of the frame itself.

3. Hack saws for cutting metal are a modification of the fret saw, using blades about one-half inch wide, and the teeth fine and slightly set. These are useful for fine wood-cutting. This refers to the American hack saw, the old English shape, being thick blade, coarse teeth and very little set, was slow cutting and heavy to work. Special saws, for instance, a long narrow saw, similar to the keyhole saw, but having half the edge of the blade at right angles to the remainder-a very useful tool for cutting a square hole. Starting with a centerbit hole, the end of the saw cut as far as was required, then the second part came into use, starting a cut at right angle to the first one, which could then be extended by using the point part again. Others are ripping and $\log$ cutting saws, having large and specially shaped teeth, and many others.

Machine saws of many kinds-circular and gang saws, band saws, veneering and other kinds - cannot be treated in this article.

Saw Teeth. If the teeth of a good saw are examined, it will be seen that each is a knife, ground at one side like a joiner's chisel, which leaves the top of the too pointed, and it will also be seen that each tooth is bent away from the central line of the blade. In some saws, each tooth is sharpened at both its edges (not at both sides of one edge), so that it cuts in the push or pull stroke. These teeth differ a little in shape from the other teeth, having only one cutting edge. The shapes of saw teeth vary with the work they have to do. While all the smaller saws cut in one direction only, rip saws and two-handed saws, also American pattern log saws, cut in both directions.

How to choose a saw. A fair outfit for a wood-worker would be: rip saw, 28 inches long, 4 points to the inch; hand saw, 26 inches long, 6 to 7 points to the inch; tenon backed saw, 14 inches long, 10 to 12 points to the inch; dovetail backed saw, 10 inches long, 14 to 18 points to the inch.

Also pad saw, sweep saw for curves, and hack saw for metal. In all saws it is important that the handle should be comfortable and fit the hand well, and the saw well balanced, i.e., in a hand saw or rip saw, when held in the cutting position, it appears to weigh less than if held in any other position. It should also be thinner at the back than at the cutting edge, apart from the set of the teeth. The blade must be capable of being bent into three-quarters of a circle without taking a permanent set. Some of the more expensive saws have smaller teeth for a few inches near the end to make a start easily in the work. In all saws, the thinner the blade is, the easier it is to work and good quality saws are always thinner than common ones of the same size and class. Look also at the finish; good saws are not sent out dull and old looking; they have a bright, highly finished appearance. For picture frames and other small work, a saw with very small teeth should be used, as it leaves the work nearly smooth. Don't buy a second-hand saw unless it is from someone who thoroughly understands a saw and can guarantee it to be a good one. New saws sold at second-hand shops are always bad, but good old saws can of ten be bought cheaply. Small size hand saws are made for amateur's tool chests, which are usually too small to hold a full-sized saw. These do not give scope for the whole arm to work. A full-sized man requires a fullsized saw to exert his strength; with a small one there is much waste of energy. For odd jobs, however, the 18-inch chest saw (a small hand saw) is a very useful tool. Backed saws in particular are liable to be twisted or buckled, so should be examined before buying.

$$
\text { USING THE SAW ON WOOD. }
$$

Always mark the work before cutting; it does not take long and saves a lot of trimming up aiterwards. For rough work a pencil mark will do, but for any exact work the mark must be made with a metal point or sharp edge, especially if cutting dovetails. In marking, allow for a shaving being taken off afterward with the plane, and use a square to get a square cut. If merelv dividing a bit of wood, it is enough to cut a line, but if the work has to fit another piece, to leave the line or pencil mark

Work must be fastened down any way so k 


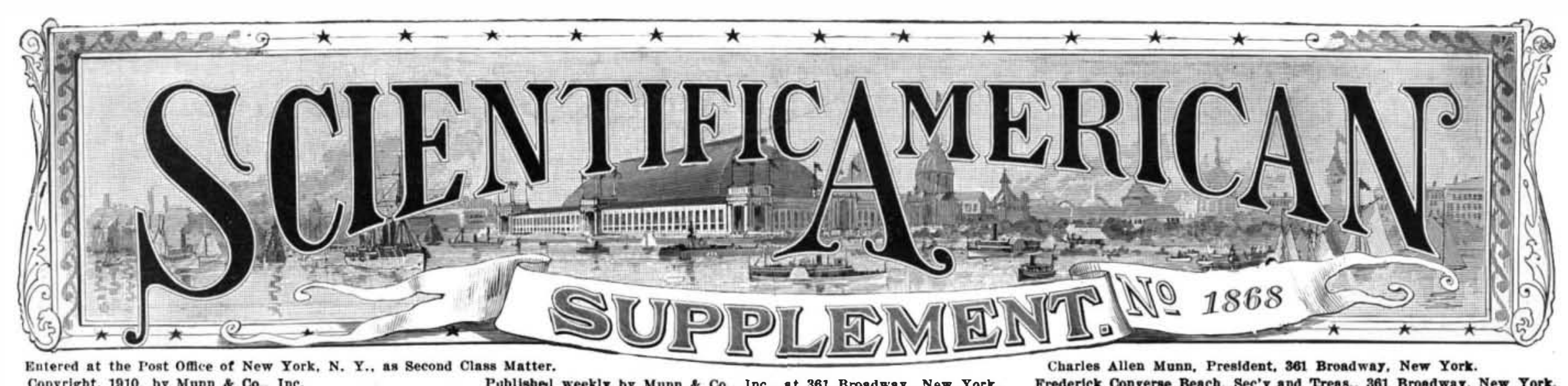

Copyright, 1910, by Munn \& Co.. Inc.

Scientific American, established 1845.

Scientific American Supplement, Vol. LXXII., No. 1868. $\}$

NEW YORK, OCTOBER 21, 1911. $\left\{\begin{array}{l}\text { Scientific American and Supplemfent, } \$ 7 \text { a year. } \\ \text { S }\end{array}\right.$

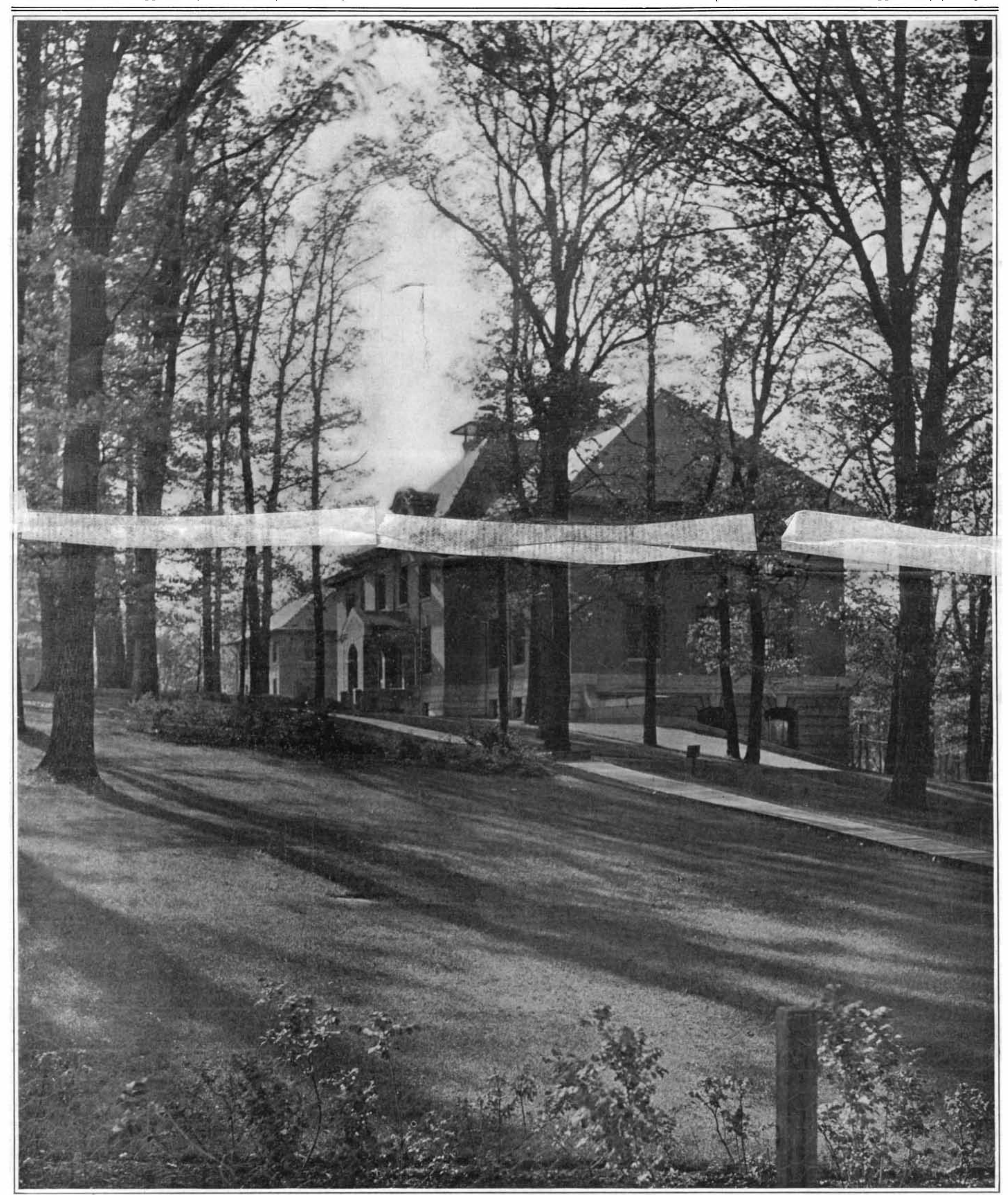

The Mechanical Laboratory and the Liquid Air Building

THE NATIONAL BUREAU OF STANDARDS AND ITS WORK. (See page 264) 